\title{
Abdominal aorta aneurysm screening program in Swietokrzyskie Voivodeship: early results
}

\author{
Marcin Piotr Żelezik', Anna Michalska', Kinga Kapturska', Aleksandra Michalska', \\ Alicja Niewiadomska', Jarosław Miszczuk ${ }^{2}$, Marcin Sadowski' \\ 'Faculty of Medicine and Health Sciences, Jan Kochanowski University, Kielce, Poland \\ ${ }^{2}$ Department of Vascular Surgery, Provincial Hospital in Kielce, Swietokrzyskie Voivodeship, Kielce, Poland
}

\begin{abstract}
Introduction: The prevalence of abdominal aorta aneurysms (AAA) is estimated to be between 1.3-12.5\% in men and 5.2\% in women, which poses a serious public health issue. Ruptured aorta aneurysm most often causes internal bleeding and ultimately leads to death. The cause of high mortality is the asymptomatic occurrence of AAA. Usually, the first symptom is its rupture

The aim of our paper is to provide a relationship between the percentage of the population reporting to the vascular surgeon and the type of residence based on the analysis of data from screening studies carried out in one of the regions of Poland.

Material and methods: Patients previously informed about the free diagnostics in the Provincial Hospital in Kielce were examined by qualified physicians with ESAOTE MyLab Seven ultrasound device. Prior to that, patients were asked to fill a questionnaire to acquire data about their risk factors, demography, and medical history.

Results: A total of 22 (7.3\%) aneurysms were found in a group of 301 patients, of which 20 (6.6\%) were found in men and $2(0.66 \%)$ in women.

Conclusions: Screening tests are an effective method to significantly improve early detection of AAAs. However, it is necessary to provide easier access to health professionals qualified to perform ultrasound examinations. It is especially important for the population of men with a family history of AAA, because they are at a higher risk of developing this pathology. The incidence rate of AAA observed in our study is consistent with the data published in worldwide literature.
\end{abstract}

Key words: abdominal aorta aneurysms, screening, prevalence

Acta Angiol 2019; 25, 3: 140-144

\section{Introduction}

The prevalence of abdominal aorta aneurysms (AAA) is estimated to be between $1.3-12.5 \%$ in men and $5.2 \%$ in women, which poses a serious public health issue $[1,2]$. The dilatation of the aorta meeting the AAA criteria is a localized, continuous increase in the diameter of the vessel by $50 \%$ relative to its normal diameter or by $3 \mathrm{~cm}$ and more [3]. Nearly $80 \%$ of patients with AAA rupture die before they get to the hospital, while in-hospital mortality rate in patients with established AAA diagnosis is about $50 \%[3,4]$. Among the risk factors for the development of AAA are age, gender, hypertension, positive family history and coronary artery disease [5]. Diabetes seems to have a protective effect on the formation of AAA $[6,7]$. One of the causes of

Address for correspondence: Marcin Piotr Żelezik, Jan Kochanowski University, The Faculty of Medicine and Health Sciences, Kielce, Poland, e-mail: marcinzelezik@gmail.com 
high mortality is the asymptomatic occurrence of AAA. Usually, its first symptom is a rupture. Mortality associated with planned open surgery of the aortic aneurysm ranges from $3 \%$ to $6 \%$, and perioperative mortality in patients with AAA rupture is $60-80 \%$. That is why in most cases the aortic aneurysm surgery is done by endovascular repair with a mortality rate of $\mathrm{I}-2 \%$ [8]. Early diagnosis and implemented treatment can protect patients from life-threatening consequences [9]. The implementation of AAA screening led to a reduction in mortality in the population observed [10-12]. So far, there has been no quantitative data about the development of AAA among the inhabitants of rural and urban areas. It is now known that the mental state of patients who are aware of their life-threatening pathology can lead to emotional disturbances, deterioration of the quality of life and hinders social and professional activity [13]. The aim of our paper is to determine the relationship between the percentage of the population reporting to the vascular surgeon and their place of residence based on the analysis of data from screening studies carried out in one of the regions of Poland.

\section{Material and methods}

Patients previously informed about the free diagnostics in the Provincial Hospital in Kielce, were examined by qualified physicians with ESAOTE MyLab Seven ultrasound device. Prior to that, patients were asked to fill a questionnaire to acquire data about their risk factors, demography, and medical history (Fig. I). The screening was held in rooms of the Department of Vascular Surgery. On arrival, the physician explained the procedures to the patient, checked their questionnaire, and answered queries. Signed informed consent was obtained.

Then, the patient had an ultrasound scan of the abdominal aorta. The maximum transverse diameter of the aorta in the transverse plane and the maximum anteroposterior diameter in the longitudinal plane were measured with calipers on the device and noted by a medical student in the appropriate text box in patients' screening program documentation. The largest diameter of these two readings was recorded as the maximum aortic diameter for each patient (Fig. 2). After that procedure, the scanned group was divided into two groups: those who had an abdominal aortic aneurysm, and those in whom no aneurysm was detected. The first group was given a referral to their family doctors, for follow up, at intervals related to the aortic size. All data had been transcribed to Excel file and then database operations have been performed. Statistics were calculated using Statistica 13 StatSoft Software.

\section{Results}

A total of $22(7.3 \%)$ aneurysms were found in a group of 30 I patients, of which $20(6.6 \%)$ were found in men and $2(0.66 \%)$ in women. Both women had no history of smoking, had a history of coronary artery disease, suffered from high blood pressure and hyperlipidemia, and were not diabetic. One of the patients had a positive family history of aneurysm. The diameters of the AAA's were $42.7 \mathrm{~mm}$ and $32 \mathrm{~mm}$.

In the group of men, a correlation between coronary disease, smoking, hyperlipidemia, diabetes and the occurrence of AAAs was not significant. A correlation between familial occurrence of AAAs and the occurrence of AAAs in patients was observed, $O R=9.00$ (95\% Cl 2.0507 to 39.4988), $\mathrm{p}=0.0036$. In this group, most AAA's $(n=14)$ were of a diameter range of 30-35 $\mathrm{mm}$. Additionally, there was one of $46 \mathrm{~mm}, 53 \mathrm{~mm}$, $41.9 \mathrm{~mm}$ and $44.6-50.3$ (on $10 \mathrm{~cm}$ length). We found also dilatation in iliac arteries ranging $15.2-50 \mathrm{~mm}$ in a left common iliac artery (LCIA) and $16.9-32 \mathrm{~mm}$ in right common iliac artery (RCIA) (Tables I-3, Fig. 3).

\section{Discussion}

Screening tests for abdominal aortic aneurysms are performed on patients fulfilling at least three of the following criteria: (1) age above 65 years, (2) male, (3) hypertension, (4) coronary artery disease, (5) hyperlipidemia, (6) smoking or (7) negative family history [14-16]. According to recent reports, the risk of developing AAA is higher in the first degree relatives of AAA patients, regardless of sex, in comparison to those without a family history of AAA [ 17]. This suggests that patients of both sexes above the age of 65 with a positive family history of AAA should be screened. In women within the risk group, there is a need for prophylactic screening, due to the higher risk of death following rupture of the aneurysm ( $88 \%, p=0.001)$, despite a twice lower risk of AAA development $(\mathrm{p}=$ $0.009)$ compared with men [18]. Based on the results of our research, we are unable to present a correlation between the risk factors and the development of AAA in female patients we examined. It is probably the result of a smaller percentage of women taking part in the study compared with men and a low number of women with AAA in this group $(n=2 ; 0.66 \%)$. Research shows that the most important risk factors of developing AAA in women are: (I) coronary artery disease [19], (2) hypertension and (3) hyperlipidemia [20].

The early results of this study correspond with papers covering a similar problem. The percentages we observed in the Swietokrzyskie Voivodeship are in accordance with observations made during the study 


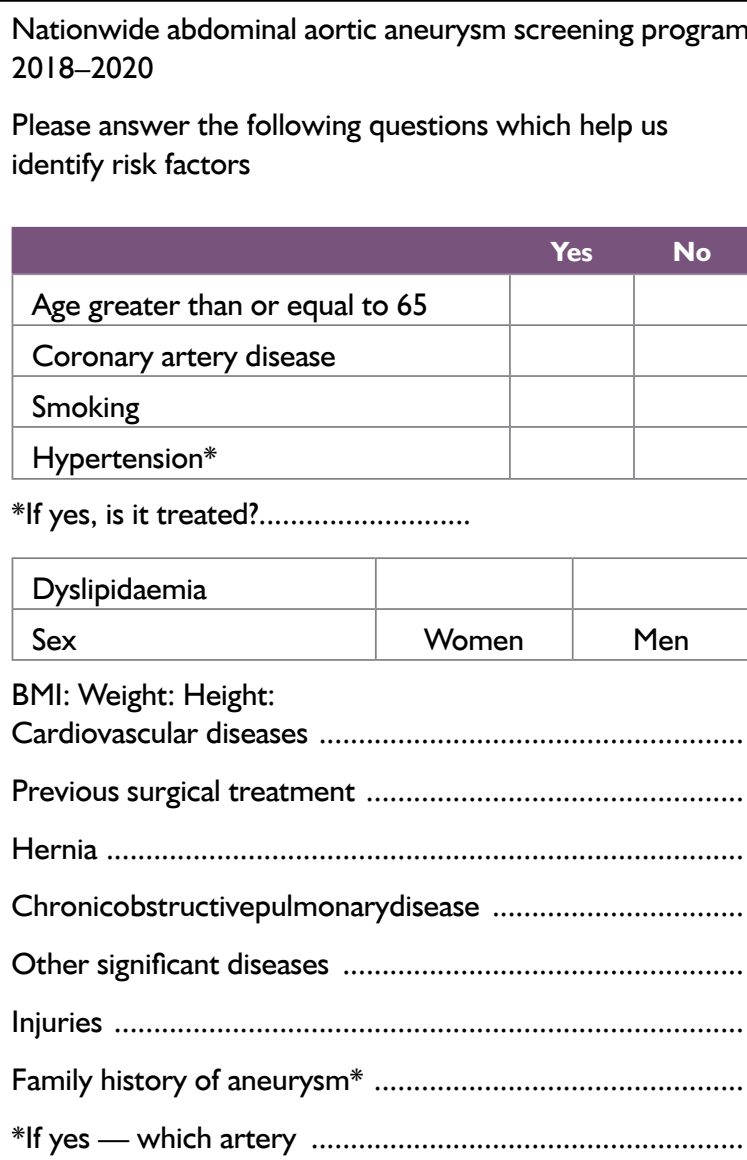

Figure I. Questionnaire

performed in Grampian in 2012-20 I [2 I]. A comparison of the results shows a similar level of interest by the population. In large cities, it was $42.6 \%$, in villages $38.9 \%$, in small towns - $18.5 \%$ and in mid-sized towns $-4 \%$. Such a distribution might indicate an insufficient level of accessibility to health care in smaller towns and villages.

Based on the above, we believe that the public in large cities is more aware of the risks of AAA and due to higher accessibility of hospitals and specialist care, the rate of detection is higher. According to Lesjak et al. [10], it is advisable to have mobile ultrasound device for AAA in areas with a population below 20,000 people, where accessibility of screening tests is limited [22, 23].

In a similar study, but based on a significantly bigger group, the results regarding the prevalence of AAA were similar to ours $(7.2 \%$ of all screened patients) [24]. This stands in agreement with another study described by Palombo et al. [25]. It also referred to the problem of decreasing the mortality rate by a successful
Examination number

Full name

Sex

Patient ID

Date of birth/age

Address

Telephone number

Medical history:

Family history

Previous treatment

Risk factors: coronary artery disease, smoking, hypertension, hyperlipidemia, male*

*Mark appropriate

Clinical examination:

USG device used:

Description:

The study included the abdominal aorta, its division, and common iliac arteries

The aneurysmal dilatation of abdominal aorta and/or iliac arteries was found/not found.*

*Mark appropriate

\begin{tabular}{|l|c|c|}
\hline Max. diameter of the aorta & & \\
\hline Max. diameter of iliac arteries & $\mathrm{R}:$ & $\mathrm{L}:$ \\
\hline
\end{tabular}

Control ultrasound examination of the abdominal aorta and iliac arteries for 6 months is indicated/ not indicated.*

*Mark appropriate

A referral to the hospital/information to the general practitioner was issued/not issued.*

*Mark appropriate

Comments:

Figure 2. Screening record

Table I. Risk factors and diameter of abdominal aorta dilatation in population of women in the study

\begin{tabular}{|l|c|c|}
\hline No & Risk factors & $\begin{array}{c}\text { Aneurysm } \\
\text { diameter }\end{array}$ \\
\hline I & Coronary artery disease, hypertension, \\
hyperlipidemia & $42.7 \mathrm{~mm}$ \\
\hline & $\begin{array}{c}\text { Coronary artery disease, hypertension, } \\
\text { hyperlipidemia, family history } \\
\text { of aneurysms }\end{array}$ & $32 \mathrm{~mm}$ \\
\hline
\end{tabular}


Table 2. Presence of risk factors in the study population

\begin{tabular}{|l|c|c|}
\hline BMI > 30 & Women & Men \\
\hline Smoking & 46 & 62 \\
\hline Hyperlipidemia & 18 & 21 \\
\hline Coronary artery disease & 127 & 143 \\
\hline High BP & 91 & 83 \\
\hline Family history of aneurysms & 119 & 152 \\
\hline Diabetes & 20 & 8 \\
\hline
\end{tabular}

Table 3. Distribution of patients according to their place of residence

\begin{tabular}{|l|c|c|}
\hline \multicolumn{1}{l}{$\begin{array}{l}\text { Population } \\
\text { (in thousands) }\end{array}$} & \multicolumn{1}{c}{$\begin{array}{c}\text { Place } \\
\text { of residence }\end{array}$} & $\begin{array}{c}\text { Number } \\
\text { of patients }\end{array}$ \\
\hline$<5$ & Village & 65 \\
\hline $5-20$ & Small towns & 33 \\
\hline $20-100$ & Mid-sized towns & 12 \\
\hline$>100$ & Large cities & 191 \\
\hline Total & & 301 \\
\hline
\end{tabular}

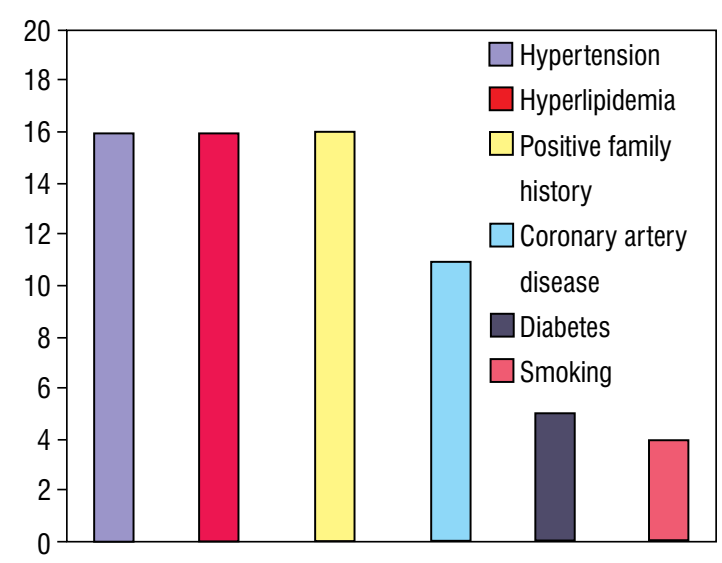

Figure 3. Risk factors of abdominal aneurysms in population of men diagnosed with AAA

screening program, which will be discussed in our next paper with the follow-up.

The presence of AAA is usually symptom-free. The Polish Cardiac Society states that on rare occasions the symptoms might be abdominal or back pains. USG tests decrease the mortality rate in men in the long run [26] by $34 \%$ (RR, 0.66 ; $95 \% \mathrm{Cl}, 0.47-0.93$; NNS, $3 \mathrm{II})$. This shows the effectiveness of screening examination for AAA using of USG devices. It is important to state that the larger size of the aneurysm and the possible later detection results in increased vascular complications and a more difficult repair of the aneurysm [27]. In older patients ( $>80$ years), the EVAR procedure survival rate is 2.53-fold lower $([\mathrm{HR}]=2.53$; $95[\mathrm{Cl}], 1.73-3.70$; $\mathrm{p}<0.00 \mathrm{I}$ ) [28]. Additionally, patients above the age of 70 are at higher risk of post-operational complications than those below 70 years of age $(10.7 \%$ vs. $7.0 \%$, $p=0.007$ ) [29].

\section{Conclusion}

During the pilot screening program, we confirmed the correlation between the family history of abdominal aorta aneurysm and a higher risk of its development. The incidence rate of AAAfound in our study is consistent with the data available in worldwide literature. Our paper focused on early, sociological data, and we concluded that people from large cities are more likely to attend screening than those from rural areas. We hope that due to the regionalization of screening for AAA in cities and rural areas, the accessibility to tests done by experienced physicians will improve.

It is especially important, as early detection of AAA leads to a decreased risk of mortality and its treatment can lead to a higher quality of life. Therefore early detection of AAA is crucial for the patients.

More data and the follow-up will be published after the pilot study ends.

\section{Conflict of interest}

None.

\section{References:}

I. Golledge J, Muller J, Daugherty A, et al. Abdominal aortic aneurysm: pathogenesis and implications for management. Arterioscler Thromb Vasc Biol. 2006; 26(I2): 2605-26/3, doi: 10.1 I6I/0I.ATV.0000245819.32762.cb, indexed in Pubmed: 16973970.

2. Zuo SW, Kui YQ, Chen F, et al. A matched case-control study of risk factors in abdominal aortic aneurysm. Journal of Peking University (Health Sciences). 20I4; 46(3): 4I2-4I6.

3. Kent KC, Zwolak RM, Egorova NN, et al. Analysis of risk factors for abdominal aortic aneurysm in a cohort of more than 3 million individuals. J Vasc Surg. 2010; 52(3): 539-548, doi: 10.1016/j. jvs.2010.05.090, indexed in Pubmed: 20630687.

4. Linné A, Forsberg J, Leander K, et al. Screening of siblings to patients with abdominal aortic aneurysms in Sweden. Scand Cardiovasc J. 20|7; 5I(3): |67-|7|, doi: 10.1080/14017431.2017.1303189, indexed in Pubmed: 28325098.

5. Shiraev T, Condous MG. Incidence and outcomes of ruptured abdominal aortic aneurysms in rural and urban Australia. ANZ J Surg. 2013; 83(II): 838-843, doi: 10.1 I I I/ans. 12080, indexed in Pubmed: 23360554.

6. Chabok M, Nicolaides A, Aslam M, et al. Risk factors associated with increased prevalence of abdominal aortic aneurysm 
in women. Br J Surg. 2016; 103(9): ||32-||38, doi: 10.1002/ /bjs. 10179 , indexed in Pubmed: 27332825.

7. Persson SE, Boman K, Wanhainen A, et al. Decreasing prevalence of abdominal aortic aneurysm and changes in cardiovascular risk factors. JVasc Surg. 2017; 65(3): 65I-658, doi: 10.1016/j. jvs.2016.08.091, indexed in Pubmed: 277935।3.

8. Moll FL, Powell JT, Fraedrich G, et al. European Society for Vascular Surgery. Management of abdominal aortic aneurysms clinical practice guidelines of the European society for vascular surgery. Eur J Vasc Endovasc Surg. 201 I; 4I Suppl I: SI-S58, doi: 10.1016/j.ejvs.2010.09.01।, indexed in Pubmed: 21215940.

9. Crilly MA, Mundie A, Bachoo P, et al. Influence of rurality, deprivation and distance from clinic on uptake in men invited for abdominal aortic aneurysm screening. Br J Surg. 2015; 102(8): 916-923, doi: 10.1002/bjs.9803, indexed in Pubmed: 25955478.

10. Lesjak MS, Flecknoe-Brown SC, Sidford JR, et al. Evaluation of a mobile screening service for abdominal aortic aneurysm in Broken Hill, a remote regional centre in far western NSW. Aust J Rural Health. 2010; 18(2): 72-77, doi: 10.1 III/j.14401584.20 10.01 | 28.x, indexed in Pubmed: 20398047.

II. Fukuda S, Watanabe H, Iwakura K, et al. Multicenter Investigations of the Prevalence of Abdominal Aortic Aneurysm in Elderly Japanese Patients With Hypertension. Circulation Journal. 2015; 79(3): 524-529, doi: 10.1253/circj.cj-14-0972.

12. Silverstein MD, Pitts SR, Chaikof EL, et al. Abdominal aortic aneurysm (AAA): cost-effectiveness of screening, surveillance of intermediate-sized AAA, and management of symptomatic AAA. Proc (Bayl Univ Med Cent). 2005; 18(4): 345-367, doi: 10.1080/08998280.2005.I1928095, indexed in Pubmed: 16252027.

13. Takagi H, Ando T, Umemoto T, et al. ALICE (All-Literature Investigation of Cardiovascular Evidence) Group. Abdominal Aortic Aneurysm Screening Reduces All-Cause Mortality: Make Screening Great Again. Angiology. 2018; 69(3): 205-211, doi: 10.1 177/0003319717693 I07, indexed in Pubmed: 28193091.

14. Krumholz HM, Keenan PS, Brush JE, et al. American Heart Association Interdisciplinary Council on Quality of Care and Outcomes Research, American College of Cardiology Foundation. Standards for measures used for public reporting of efficiency in health care: a scientific statement from the American Heart Association Interdisciplinary Council on Quality of Care and Outcomes research and the American College of Cardiology Foundation. J Am Coll Cardiol. 2008; 52(18): 1518-1526, doi: 10.1016/j.jacc.2008.09.004, indexed in Pubmed: 19017522.

15. Altobelli E, Rapacchietta L, Profeta VF, et al. Risk Factors for Abdominal Aortic Aneurysm in Population-Based Studies: A Systematic Review and Meta-Analysis. Int J Environ Res Public Health. 2018; 15(I2), doi: $10.3390 /$ ijerph I5 |22805, indexed in Pubmed: 30544688.

16. Aune D, Schlesinger S, Norat T, et al. Tobacco smoking and the risk of abdominal aortic aneurysm: a systematic review and meta-analysis of prospective studies. Sci Rep. 2018; 8(I): 14786, doi: 10.1038/s4 1598-018-32 100-2, indexed in Pubmed: 30283044.

17. Ying AJ, Affan ET. Abdominal Aortic Aneurysm Screening: A Systematic Review and Meta-analysis of Efficacy and Cost. Ann Vasc
Surg. 2019; 54: 298-303.e3, doi: 10.1016/j.avsg.2018.05.044, indexed in Pubmed: 30081169.

18. Durieux R, Van Damme H, Labropoulos N, et al. High prevalence of abdominal aortic aneurysm in patients with three-vessel coronary artery disease. Eur J Vasc Endovasc Surg. 2014; 47(3): 273-278, doi: 10.1016/j.ejvs.2013.12.011, indexed in Pubmed: 24456737.

19. García SLB. Abdominal aortic aneurysm. Prevalence and associated risk factors in a population of patients hospitalised in Internal Medicine. Revista Clínica Española (English Edition). 2018; 218(9): 455-460, doi: 10.1016/j.rceng.2018.04.005.

20. Itoga N, Rothenberg K, Suarez P, et al. VESS07. Metformin Prescription Status and Abdominal Aortic Aneurysm Disease Progression in the U.S. Veteran Patient Population. Journal of Vascular Surgery. 2018; 67(6): e52, doi: 10.1016/j. jvs.2018.03.019.

21. Kniemeyer HW, Kessler T, Reber PU, et al. Treatment of ruptured abdominal aortic aneurysm, a permanent challenge or a waste of resources? Prediction of outcome using a multi-organ-dysfunction score. Eur J Vasc Endovasc Surg. 2000; 19(2): 190-196, doi: 10.1053/ejvs.1999.0980, indexed in Pubmed: 10727370.

22. Ashton HA, Gao L, Kim LG, et al. Fifteen-year follow-up of a randomized clinical trial of ultrasonographic screening for abdominal aortic aneurysms. Br J Surg. 2007; 94(6): 696-70I, doi: 10. 1002/bjs.5780, indexed in Pubmed: 175 I 4666.

23. Lindholt JS, Sørensen J, Søgaard R, et al. Long-term benefit and cost-effectiveness analysis of screening for abdominal aortic aneurysms from a randomized controlled trial. Br J Surg. 2010 97(6): 826-834, doi: 10.1002/bjs.700I, indexed in Pubmed: 20473995

24. Norman P, Jamrozik K, Lawrence-Brown M, et al. Population based randomised controlled trial on impact of screening on mortality from abdominal aortic aneurysm. BMJ. 2004; 329(7477): I259, doi: 10. I 136/bmj.329.7477. I259.

25. Palombo D, Lucertini G, Pane B, et al. Screening for abdominal aortic aneurysm. Questions and results. Acta Chir Belg. 2011; III (I): 7-II, indexed in Pubmed: 2I 520780.

26. Stanišić MG, Rzepa T, Gawrońska A, et al. Personal resources and satisfaction with life in Marfan syndrome patients with aortic pathology and in abdominal aortic aneurysm patients. Kardiochir Torakochirurgia Pol. 2018; 15(I): 27-30, doi: 10.5114/ /kitp.2018.74672, indexed in Pubmed: 2968I 958.

27. Overbey DM, Glebova NO, Chapman BC, et al. Morbidity of endovascular abdominal aortic aneurysm repair is directly related to diameter. J Vasc Surg. 2017; 66(4): 1037-1047. e7, doi: 10.1016/j.jvs.2017.01.058, indexed in Pubmed: 28433338.

28. Png CY, Tadros RO, Faries PL, et al. The Effect of Age on Post-EVAR Outcomes. Ann Vasc Surg. 2016; 35: 156-162, doi: 10.1016/j.avsg.2016.01.022, indexed in Pubmed: 27236092.

29. Hye RJ, Janarious AU, Chan PH, et al. Survival and Reintervention Risk by Patient Age and Preoperative Abdominal Aortic Aneurysm Diameter after Endovascular Aneurysm Repair. Ann Vasc Surg. 2019; 54: 21 5-225, doi: 10.1016/j.avsg.2018.05.053, indexed in Pubmed: 30081 171. 